\title{
Quantification of Ventricular Repolarization Variation for Sudden Cardiac Death Risk Stratification in Atrial Fibrillation
}

\author{
Alba Martín-Yebra, Pablo Laguna, Iwona Cygankiewicz, Antoni Bayés-de-Luna, Enrico G. Caiani \\ and Juan Pablo Martínez
}

\begin{abstract}
Objective: Atrial fibrillation (AF) rhythm gives rise to an irregular response in ventricular activity, preventing the use of standard ECG-derived risk markers based on ventricular repolarization heterogeneity under this particular condition. In this study we proposed new indices to quantify repolarization variations in AF patients, assessing their stratification performance in a chronic heart failure (CHF) population with AF. Methods: We developed a method based on a selective bin averaging technique. Consecutive beats preceded by a similar $R R$ interval were selected, from which the average variation within the ST-T complex for each $R R$ range was computed. We proposed two sets of indices: (i) the 2-beat index of ventricular repolarization variation, $\left(\mathrm{I}_{\mathrm{v}_{2}}\right)$, computed from pairs of stable consecutive beats; and (ii) the 3-beat indices of ventricular repolarization variation, computed in triplets of stable consecutive beats $\left(I_{v 3}\right)$. Results: These indices showed a significant association with sudden cardiac death (SCD) outcome in the study population. In addition, risk assessment based on the combination of the proposed indices improved stratification performance compared to their individual potential. Conclusion: Patients with enhanced ventricular repolarization variation computed in terms of the proposed indices were successfully associated to a higher SCD incidence in our study population, evidencing their prognostic value. Significance: using a simple ambulatory ECG recording, it is possible to stratify AF patients at risk of SCD, which may help cardiologists in adopting most effective therapeutic strategies, with a positive impact in both the patient and healthcare systems.
\end{abstract}

Index Terms-Electrocardiogram (ECG), ventricular repolarization instability, atrial fibrillation (AF), sudden cardiac death (SCD).

\section{INTRODUCTION}

This work was supported by project DPI2016-75458-R funded by MINECO and FEDER and by Gobierno de Aragón and European Social Fund (EU) through Biomedical Signal Interpretation and Computational Simulation (BSICoS) Reference Group (T39-17R). By CIBER in Bioengineering, Biomaterials \& Nanomedicne (CIBER-BBN) through Instituto de Salud Carlos III and FEDER (Spain) and by the Italian Space Agency (contract 2013-033-R.0, recipient E. Caiani). The computation was performed by the ICTS NANBIOSIS, specifically by the High Performance Computing Unit of the CIBER-BBN at the University of Zaragoza.

*A. Martín-Yebra is with CIBER-BBN and with BSICoS group, I3A, IIS Aragón, Universidad de Zaragoza, Zaragoza, Spain (correspondence e-mail: amartiny@unizar.es). I. Cygankiewicz is with Department of Electrocardiology, Medical University of Lodz, Lodz, Poland. A. Bayés-de-Luna is with Institut Català de Ciències Cardiovasculars, Santa Creu i Sant Pau Hospital, Barcelona, Spain. E. Caiani is with Dipartimento di Elettronica, Informazione e Bioingegneria, Politecnico di Milano, Milano, Italy. P. Laguna and JP. Martínez are with BSICoS group, I3A, IIS Aragón, Universidad de Zaragoza, Zaragoza, Spain, and with CIBER-BBN, Spain.

Manuscript received $\mathrm{xx}$; revised $\mathrm{xx}$
A TRIAL FIBRILLATION (AF) is the most prevalent sustained arrhythmia and it has become one of the most important public health issues in developed countries. It is expected to double its incidence by 2030 [1, 2], representing the major cause of hospitalizations in elderlies ( $\geq 65$ years), together with chronic heart failure (CHF). Indeed, AF and $\mathrm{CHF}$, which frequently occur together, are both leading causes of morbidity and mortality worldwide, with an increasing incidence and prevalence with age, having an adverse impact in the quality of life of these patients [3].

It has been shown that most deaths occurring in AF patients, even being properly anticoagulated, were actually not related to stroke, thus raising the need for identifying other possible actors and effective interventions to reduce mortality in AF [4]. In fact, recent data have pointed out the independent contribution of AF to sudden cardiac death (SCD) risk [5-8], most of these deaths appearing as a consequence of malignant ventricular arrhythmias. Current therapeutic alternatives in this target population aim to restore and maintain sinus rhythm and to keep the ventricular rate under control [3]. In particular, implantable cardioverter-defibrillators (ICDs) can protect from SCD by terminating ventricular tachyarrhythmias. However, it is difficult to identify those patients who could potentially benefit from this therapy, especially in the AF setting.

The predictive value of electrical instability assessed on the electrocardiogram (ECG) signal has been widely studied. Specifically, enhanced ventricular repolarization heterogeneities, which can be quatified through the analysis of the T-wave of the ECG, have been associated with SCD risk and several non-invasive markers have been proposed [9-11]. However, the occurrece times of ventricular contractions during AF are highly irregular and this singularity prevents from the use of most of those indices, including QT-interval duration and dispersion [12, 13], the Tpeak-to-Tend interval [14, 15], T-wave alternans (TWA) [16], or the recently proposed T-wave morphology restitution (TMR) [17], in the AF population, as they require the patient to be in sinus rhythm to be properly assessed.

From the hypothesis that a non-invasive stratification of $\mathrm{AF}$ patients at risk of SCD is possible by assessing ventricular repolarization in the electrocardiogram signal, the aim of this study is to propose new measurements of ventricular repolarization beat-to-beat variations, suitable for ECG recordings during $\mathrm{AF}$, using a selective heart-rate bin averaging technique, and to evaluate whether the proposed indices provide prognos- 
tic value for SCD in a CHF population with AF. A preliminary version of this work has been reported in [18].

\section{METhODS}

\section{A. Preprocessing}

First, ventricular complexes were detected in each ECG recording using the Aristotle software [19] and the $R R$ series along the whole recording were computed, defining the $R R$ interval associated to the $i^{\text {th }}$ beat as illustrated in Fig. 1.

Then, after baseline wander removal by high-pass linear filtering, the ECG was low-pass filtered (cut-off frequency of $15 \mathrm{~Hz}$ ) in order to cancel noise out of the T-wave frequency band, and down-sampled by a factor of 2. Finally, the vectormagnitude of the vectorcardiogram (VCG) signal was also obtained using the three orthogonal leads $(\mathrm{X}, \mathrm{Y}, \mathrm{Z})$.

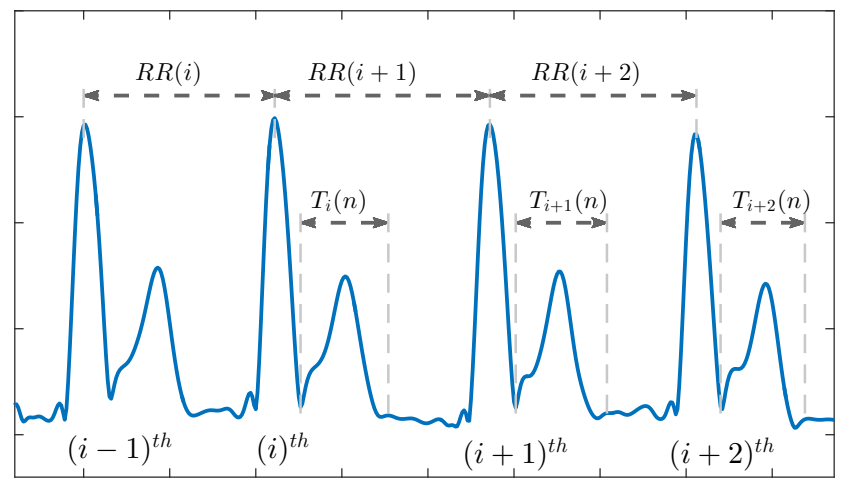

Fig. 1. Illustration of the vector-magnitude of an ECG signal with main explicative intervals.

\section{B. Selective beat averaging}

We proposed the use of a concept similar to selective beat averaging technique [20] to compute the average ventricular repolarization variation in consecutive beats grouped by bins of similar $R R$. The algorithm proceeds as follows:

1) After automatic identification, ventricular $Q R S-T$ complexes were grouped based on their associated $R R$ interval. To do that, we first define the set $S$ by all triplets of consecutive beats within the Holter recording: $(i, i+1, i+2)$, for any initial beat $i$. We then subdivide the considered range of $R R s$ (initially between $\min R R=300 \mathrm{~ms}$ and $\max R R=1600 \mathrm{~ms})$ into $K$ bins, denoted as $I_{k},(k=1, \cdots, K)$. For each bin, an associated subset $S_{k}$ is defined as containing those triplets in $S$ whose first element $i$ is included in $I_{k}$, and whose difference between consecutive $R R$ intervals (i.e, between $R R(i+1)$ and $R R(i)$, and between $R R(i+2)$ and $R R(i+1))$ is lower than half of the bin width. That is:

$$
\begin{gathered}
S_{k}=\{(i, i+1, i+2)\} \\
\text { where }\left\{R R(i) \in I_{k},|R R(i+1)-R R(i)| \leq \frac{\delta}{2},\right. \\
\left.|R R(i+2)-R R(i+1)| \leq \frac{\delta}{2}\right\} \\
I_{k}=\{R R(i): \min R R+(k-1) \delta \leq R R(i) \\
\leq \min R R+k \delta\}
\end{gathered}
$$

We set the bin width as $\delta=40 \mathrm{~ms}$. In this step, basically triplets of consecutive beats that were preceded by a similar $R R$ interval were selected, thus allowing the assumption of stability.

2) For each triplet of beats included in $S_{k}$, two T-wave variation waveforms, $\Delta T_{1}(n)$ and $\Delta T_{2}(n)$, were computed as the difference between each pair of consecutive ST-T complexes:

$$
\begin{aligned}
& \Delta T_{(i, 1)}(n)=T_{(i+1)}(n)-T_{(i)}(n) \\
& \Delta T_{(i, 2)}(n)=T_{(i+2)}(n)-T_{(i+1)}(n), \quad n=1, \ldots, N
\end{aligned}
$$

where $T_{i}(n)$ denotes the ST-T complex of the $i^{t h}$ beat (Fig. 1), set as a fixed window of $300 \mathrm{~ms}$ after QRS complex end, with $n$ the index of the sample within the complex.

3) From $\Delta T_{1}(n)$ and $\Delta T_{2}(n)$ waveforms, two measurements of ventricular variability were derived:

$$
\begin{aligned}
& v_{i}^{+}(n)=\frac{\Delta T_{(i, 1)}(n)+\Delta T_{(i, 2)}(n)}{2} \\
& v_{i}^{-}(n)=\frac{\Delta T_{(i, 1)}(n)-\Delta T_{(i, 2)}(n)}{2},
\end{aligned}
$$

where $v_{i}^{+}(n)$ quantifies the average repolarization variation in each triplet, and $v_{i}^{-}(n)$ measures the alternant repolarization variation along the three consecutive stable beats. In the following, we will use vector notation, being $\boldsymbol{v}_{i}^{+}$and $\boldsymbol{v}_{i}^{-}$the column vectors whose elements are the samples of $v_{i}^{+}(n)$ and $v_{i}^{-}(n)$, respectively.

4) These repolarization variation waveforms are of low amplitude, usually as low as a few microvolts, and therefore, we propose to apply signal averaging to enhance and quantify them in a given bin $I_{k}$. Before averaging, we need to aling all waveforms, similarly to what was done in [21] for TWA analysis. In this case, the phasealigned waveforms, $\boldsymbol{v}_{i}^{a+}$ and $\boldsymbol{v}_{i}^{a-}$, were estimated as:

$$
\begin{aligned}
& \boldsymbol{v}_{i}^{a+}=\operatorname{sign}\left(\boldsymbol{v}_{i}^{+T} \mathbf{w}_{1}^{+}\right) \boldsymbol{v}_{i}^{+} \\
& \boldsymbol{v}_{i}^{a-}=\operatorname{sign}\left(\boldsymbol{v}_{i}^{-T} \mathbf{w}_{1}^{-}\right) \boldsymbol{v}_{i}^{-}
\end{aligned}
$$

where $\mathbf{w}_{1}^{+}$is the first eigenvector associated to the largest eigenvalue $\lambda_{1}^{+}$of the correlation matrix $\mathbf{R}_{\boldsymbol{v}^{+}}$ estimated from all variation vectors $\boldsymbol{v}_{i}^{+}$, and $\mathbf{w}_{1}^{-}$is the first eigenvector associated to the largest eigenvalue $\lambda_{1}^{-}$of the correlation matrix $\mathbf{R}_{\boldsymbol{v}^{-}}$estimated from all variation vectors $\boldsymbol{v}_{i}^{-}$(a more detailed description can be found in [21]). 
5) Finally, the average repolarization variation associated to the $k^{t h}$ bin, i.e. the subset $S_{k}$, denoted as $\overline{\boldsymbol{v}}_{k}^{+}$is defined as the median waveform of all $\boldsymbol{v}_{i}^{a+}$ computed for the respective bin. The alternant variation waveform associated to the same bin, denoted as $\overline{\boldsymbol{v}}_{k}^{-}$, is obtained in an analogous way.

\section{The 3-beat indices of ventricular repolarization variation}

Based on these two measurements, we proposed two indices to characterize the repolarization variation in the 24-hour Holter recording: the index of average repolarization variation and the index of alternant variation within sequences of 3 beats, $\mathrm{I}_{\mathrm{v} 3}^{+}$and $\mathrm{I}_{\mathrm{v} 3}^{-}$, respectively. They were calculated as the mean absolute value of the average waveform of all bins (of all $\overline{\boldsymbol{v}}_{k}^{a+}$ and $\overline{\boldsymbol{v}}_{k}^{a-}$, respectively). That is:

$$
\begin{aligned}
& \mathrm{I}_{\mathrm{v} 3}^{+}=\frac{1}{N} \sum_{n=1}^{N}\left|\frac{1}{K} \sum_{k=1}^{K} \bar{v}_{k}^{a+}(n)\right| \\
& \mathrm{I}_{\mathrm{v} 3}^{-}=\frac{1}{N} \sum_{n=1}^{N}\left|\frac{1}{K} \sum_{k=1}^{K} \bar{v}_{k}^{a-}(n)\right|
\end{aligned}
$$

with $N$ the number of samples in the ST-T complex.

Both indices were also computed on each individual lead, denoted as $\mathrm{I}_{\mathrm{v}_{3} \mathrm{X}}^{+}, \mathrm{I}_{\mathrm{v} 3 \mathrm{Y}}^{+}, \mathrm{I}_{\mathrm{v}_{3} \mathrm{Z}}^{+}, \mathrm{I}_{\mathrm{v} 3 \mathrm{X}}^{-}, \mathrm{I}_{\mathrm{V} 3 \mathrm{Y}}^{-}$and $\mathrm{I}_{\mathrm{v}_{3 Z}}^{-}$for leads $X$, $Y$ and $Z$, respectively. Additionally, we defined the heartrate restricted indices, $\mathrm{I}_{\mathrm{v}_{3}}^{+90}$ and $\mathrm{I}_{\mathrm{v} 3}^{-90}$, by including only bins associated to heart rates faster than 90 beats/min (i.e. $R R<660 \mathrm{~ms})$.

\section{The 2-beat index of ventricular repolarization variation}

Instantaneous beat-to-beat repolarization variation in 2-beat sequences, denoted as $I_{v_{2}}$, was also computed, following a similar approach, but considering only pairs of 2 consecutive beats $(i, i+1)$ with similar $R R$. Each subset $S_{k}^{\prime}$ was defined as:

$$
\begin{gathered}
S_{k}^{\prime}=\{(i, i+1)\} \\
\text { where }\left\{R R(i) \in I_{k},|R R(i+1)-R R(i)| \leq \frac{\delta}{2}\right\}
\end{gathered}
$$

In this case, a single T-wave variation waveform was computed for each pair of beats in $S_{k}^{\prime}$ as $\Delta T_{i}(n)=T_{(i+1)}(n)-$ $T_{(i)}(n)$. Finally, the $\mathrm{I}_{\mathrm{v} 2}$ was defined as:

$$
\mathrm{I}_{\mathrm{V} 2}=\frac{1}{N} \sum_{n=1}^{N}\left|\frac{1}{K} \sum_{k=1}^{K} \overline{\Delta T}_{k}^{a}(n)\right|
$$

where $\overline{\Delta T}_{k}^{a}(n)$, analogous to the computation of the previous indices, is the median variation waveform of all $\Delta T_{i}(n)$ included in the corresponding subset $S_{k}^{\prime}$, after being aligned in sign.

Also in this case, the index $\mathrm{I}_{\mathrm{v} 2}^{90}$, including bins associated to heart rates faster than 90 beats/min, was computed.

\section{E. Statistical analysis}

Data are presented as median $\left(25^{\text {th }} ; 75^{\text {th }}\right.$ percentiles $)$ for continuous variables and as number (percentage) for categorical variables, unless otherwise specified.

We used the bidirectional Mann-Whitney and Fisher exact tests to evaluate differences between SCD and non-SCD groups in quantitative and categorical data, respectively. Survival probability was estimated by the Kaplan-Meier method and the association between groups and SCD outcome by the log-rank test. Finally, univariate Cox proportional hazard analyses were performed in order to evaluate the potential prognostic value of the proposed indices for SCD stratification. Our study population is reduced in terms of SCD events $(n=19)$ and this limited the construction of a multivariate model with more than two covariates (at least 10 events are required for each covariate included in the model [22]). After univariate analysis, bivariate Cox proportional models combining the indices with other clinical and pharmacological variables that resulted associated to SCD in univariate analysis were constructed. For all tests, a p-value $\leq 0.05$ was considered as statistically significant.

\section{DATA SET}

The prognostic value of the indices has been assessed by analyzing ambulatory ECG recordings (24-h Holter) from CHF patients with permanent AF. Patients were recruited in the multicenter, prospective MUSIC (MUerte Súbita en Insuficiencia Cardiaca) study, which aimed at assessing risk predictors for cardiac mortality in heart failure [23]. The recruitment took place between April 2003 and December 2004 at eight Spanish university hospitals. The initial cohort included 992 consecutive patients with symptomatic CHF, belonging to functional classes II and III according to the New York Heart Association (NYHA) classification, with both preserved and reduced left ventricular ejection fraction (LVEF). Data for demographic and clinical characteristics and medication were collected at enrolment. For each subject, a 24-hour Holter ECG recording containing three (95.3\%) or two orthogonal leads (X, Y, Z) sampled at $200 \mathrm{~Hz}$ were acquired with SpiderView recorders (ELA Medical, Sorin Group, Paris, France).

From the original cohort, the 171 patients (128 males, $68.9 \pm 10.4$ years) with permanent $\mathrm{AF}$ were selected for this study. In this AF subgroup, the $71.3 \%$ of patients were in NYHA class II, with average LVEF of $39.4 \pm 15.7 \%$, half of them $(50.9 \%)$ with reduced LVEF $(\leq 35 \%)$. Ischemic etiology of CHF was present in $26.9 \%$ of patients. Finally, intraventricular conduction delay (QRS duration $>0.12 \mathrm{~s}$ ) was present in 71 patients. The main patient characteristics of the study group are summarized on Table I.

Follow-up period was conducted for an average of 48 months, including periodic visits every 6 months. At the end of the follow-up period, the study group included 19 events of SCD, 24 deaths due to a different cardiac origin, 20 non-cardiac deaths and 108 survivors. SCD was defined by the study's End-point Committee. The study protocol was approved by the institutional ethical boards and all patients sing informed consent [23]. 

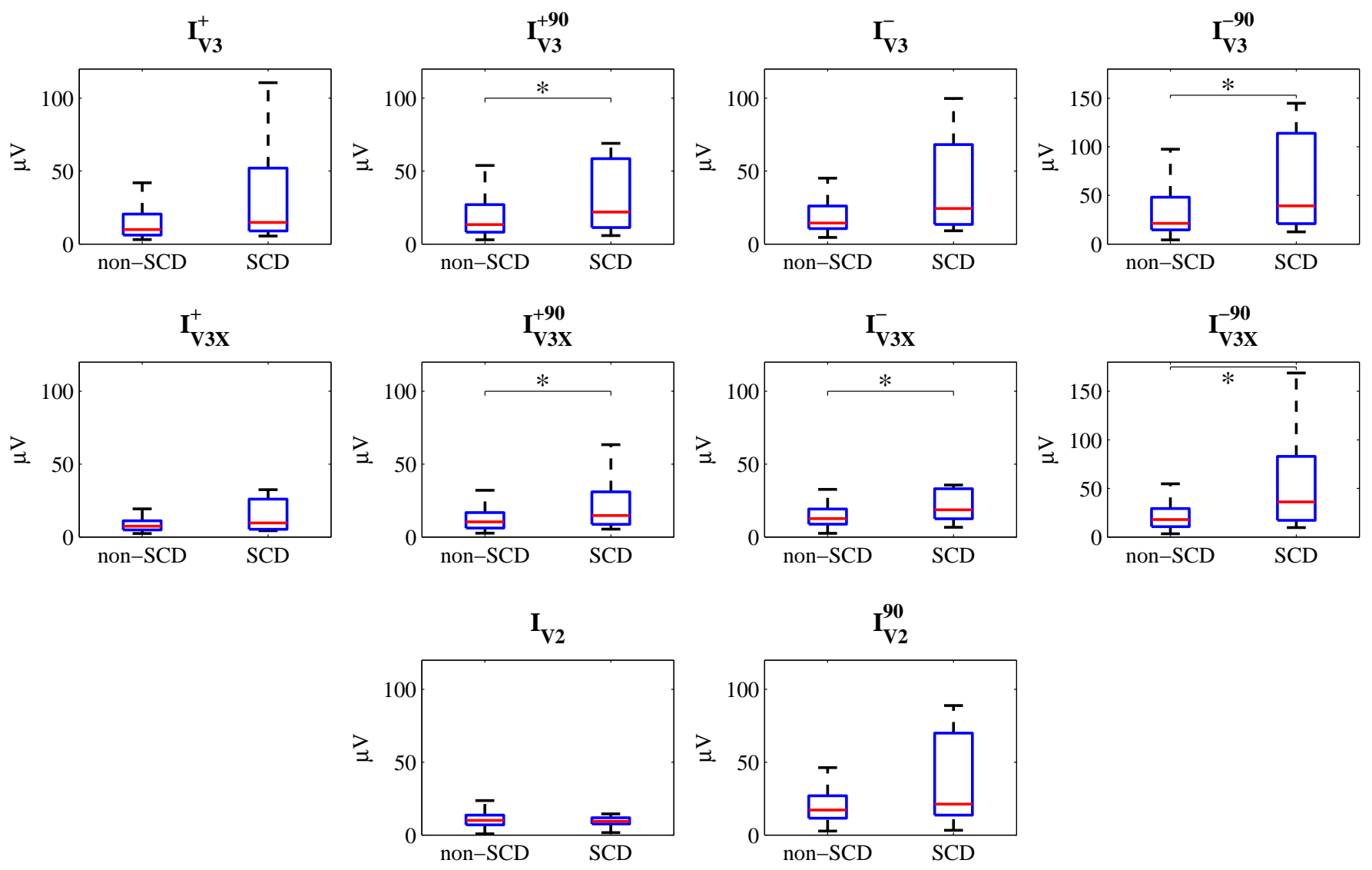

Fig. 2. Distribution of $I_{\sqrt{ } 3}$ and $I_{V 2}$ indices for non-SCD and SCD groups. *: $p \leq 0.05$ non-SCD vs $S C D$.

TABLE I

CLINICAL CHARACTERISTICS OF THE STUDY POPULATION. DATA ARE EXPRESSED AS MEAN \pm STANDARD DEVIATION AND AS ABSOLUTE FREQUENCIES (PERCENTAGE).

\begin{tabular}{lccc}
\hline \hline & $\begin{array}{c}\text { Overall population } \\
(\mathrm{n}=171)\end{array}$ & $\begin{array}{c}\text { SCD group } \\
(\mathrm{n}=19)\end{array}$ & $\begin{array}{c}\text { Non-SCD group } \\
(\mathrm{n}=152)\end{array}$ \\
\hline Age (years) & $68.9 \pm 10.4$ & $69.2 \pm 10.5$ & $68.9 \pm 10.4$ \\
Gender (males) & $128(74.8 \%)$ & $16(84.2 \%)$ & $112(73.7 \%)$ \\
LVEF $\leq 35 \%$ & $87(50.9 \%)$ & $14(73.7 \%)$ & $73 *(48.0 \%)$ \\
NYHA class III & $49(28.6 \%)$ & $5(26.3 \%)$ & $44(28.9 \%)$ \\
Diabetes & $50(29.2 \%)$ & $6(31.6 \%)$ & $44(28.9 \%)$ \\
Ischemic etiology & $46(26.9 \%)$ & $10(52.6 \%)$ & $36 *(23.7 \%)$ \\
Beta-blockers & $100(58.5 \%)$ & $9(47.3 \%)$ & $91(59.9 \%)$ \\
Amiodarone & $25(14.6 \%)$ & $2(10.5 \%)$ & $23(15.1 \%)$ \\
Digoxin & $106(62.0 \%)$ & $11(57.9 \%)$ & $95(62.5 \%)$ \\
QRSd $\geq 120 \mathrm{~ms}$ & $71(41.5 \%)$ & $11(57.9 \%)$ & $60(39.5 \%)$ \\
\hline \hline * $<\leq 0.05 \mathrm{SCD}$ vs Non-SCD groups & & \\
\hline
\end{tabular}

*p $\leq 0.05$ SCD vs Non-SCD groups

SCD: Sudden cardiac death

LVEF: Left ventricular ejection fraction

NYHA: New York Heart Association; QRSd: QRS duration.

\section{RESUlts}

Distributions of $\mathrm{I}_{\mathrm{v} 3}^{+}, \mathrm{I}_{\mathrm{v} 3}^{-}, \mathrm{I}_{\mathrm{v} 3}^{+90}$ and $\mathrm{I}_{\mathrm{v} 3}^{-90}$ are presented in Fig. 2, for both SCD and non-SCD groups of patients. SCD outcome was associated in most cases with higher values, that is, with higher repolarization variability. $\mathrm{I}_{\mathrm{v} 3}^{+}$and $\mathrm{I}_{\mathrm{v} 3}^{-}$were not computable in 8 out of 171 Holter recordings (4.7\%) as only
2 leads were available and the vector-magnitude of the VCG could not be computed. Moreover, the additional restriction imposed when computing $\mathrm{I}_{\mathrm{v} 3}^{+90}$ and $\mathrm{I}_{\mathrm{v} 3}^{-90}$, by considering only bins of $R R \mathrm{~s}$ associated to $\mathrm{HR} \geq 90$ beats $/ \mathrm{min}$, led to the exclusion of 7 additional recordings $(8.7 \%$ of the total population) in which there was not any suitable triplet of beats accomplishing the conditions in that range. Additionally, distributions of $\mathrm{I}_{\mathrm{V} 2}$ and $\mathrm{I}_{\mathrm{v} 2}^{90}$ values for both groups are also presented in Fig. 2. While $\mathrm{I}_{\mathrm{v}_{2}}$ values did not present significant differences between SCD and non-SCD groups, $\mathrm{I}_{\mathrm{v}_{2}}^{90}$ was higher in SCD group in comparison with the non-SCD group, though not statistically significant $(21.21(13.7 ; 69.93) \mu \mathrm{V}$ vs 17.1 $(11.49 ; 26.296) \mu \mathrm{V}, \mathrm{NS})$. In this case, $\mathrm{I}_{\mathrm{v} 2}^{90}$ was not computable in 10 out of 171 recordings, either because the recording had only 2 leads ( 8 recordings) or because no pair of beats was found suitable for the analysis ( 2 recordings).

The individual predictive value of each index was tested. To do that, patients were classified by setting a risk threshold $t h_{\text {risk }}$ corresponding to the third quartile (Q3) of the total distribution of $\mathrm{I}_{\mathrm{v} 3}$ values (i.e. as $\mathrm{I}_{\mathrm{v} 3}(+)$ if $\mathrm{I}_{\mathrm{v} 3} \geq t h_{\text {risk }}$ and as $\mathrm{I}_{\mathrm{v} 3}(-)$, otherwise). Thus, for each index, the positive $(+)$ group will contain the $25 \%$ of patients with the highest values. Univariate analysis demonstrated that $\mathrm{I}_{\mathrm{v} 3 \mathrm{X}}^{+}, \mathrm{I}_{\mathrm{v} 3 \mathrm{X}}^{+90}, \mathrm{I}_{\mathrm{v} 3}^{-90}$, $\mathrm{I}_{\mathrm{v}_{3 \mathrm{X}}}^{+}$and $\mathrm{I}_{\mathrm{V} 3 \mathrm{X}}^{-90}$ were successfully associated to SCD outcome (see Table II). Also in this case, patients were classified as 
TABLE II

ASSOCIATION OF $\mathrm{I}_{\mathrm{V} 3}$ AND I $\mathrm{I}_{\mathrm{V} 2}^{90}$ INDICES WITH MORTALITY IN PATIENTS WITH HEART FAILURE AND ATRIAL FIBRILLATION.

\begin{tabular}{|c|c|c|c|c|c|c|c|c|}
\hline & \multicolumn{2}{|c|}{ SCD } & \multicolumn{2}{|c|}{ PFD } & \multicolumn{2}{|c|}{ non-CD } & \multicolumn{2}{|c|}{ Total mortality } \\
\hline & $\begin{array}{c}\text { HaR } \\
(95 \% \mathrm{CI})\end{array}$ & p-value & $\begin{array}{c}\text { HaR } \\
(95 \% \mathrm{CI})\end{array}$ & p-value & $\begin{array}{c}\text { HaR } \\
(95 \% \text { CI })\end{array}$ & p-value & $\begin{array}{c}\text { HaR } \\
(95 \% \mathrm{CI})\end{array}$ & p-value \\
\hline $\mathrm{I}_{\mathrm{V} 3}^{+} \geq 22.650 \mu \mathrm{V}$ & $\begin{array}{c}2.45 \\
(0.98,6.08)\end{array}$ & 0.054 & $\begin{array}{c}1.97 \\
(0.83,4.69)\end{array}$ & 0.126 & $\begin{array}{c}0.40 \\
(0.09,1.75)\end{array}$ & 0.224 & $\begin{array}{c}1.46 \\
(0.84,2.54)\end{array}$ & 0.177 \\
\hline $\mathrm{I}_{\mathrm{V} 3}^{+90} \geq 32.517 \mu \mathrm{V}$ & $\begin{array}{c}2.15 \\
(0.83,5.55)\end{array}$ & 0.113 & $\begin{array}{c}1.98 \\
(0.83,4.73)\end{array}$ & 0.123 & $\begin{array}{c}0.23 \\
(0.03,1.75)\end{array}$ & 0.156 & $\begin{array}{c}1.38 \\
(0.77,2.46)\end{array}$ & 0.281 \\
\hline $\mathrm{I}_{\mathrm{V} 3 \mathrm{X}}^{+} \geq 11.752 \mu \mathrm{V}$ & $\begin{array}{c}\mathbf{2 . 9 7} \\
(1.21,7.31)\end{array}$ & 0.018 & $\begin{array}{c}1.12 \\
(0.44,2.81)\end{array}$ & 0.816 & $\begin{array}{c}1.12 \\
(0.41,3.07)\end{array}$ & 0.832 & $\begin{array}{c}1.55 \\
(0.91,2.64)\end{array}$ & 0.106 \\
\hline $\mathrm{I}_{\mathrm{V} 3 \mathrm{X}}^{+90} \geq 17.332 \mu \mathrm{V}$ & $\begin{array}{c}\mathbf{2 . 9 7} \\
(1.17,7.53) \\
\end{array}$ & 0.022 & $\begin{array}{c}2.27 \\
(0.99,5.21) \\
\end{array}$ & 0.051 & $\begin{array}{c}1.18 \\
(0.38,3.63) \\
\end{array}$ & 0.772 & $\begin{array}{c}\mathbf{2 . 0 9} \\
(1.23,3.56) \\
\end{array}$ & 0.007 \\
\hline $\mathrm{I}_{\mathrm{V} 3}^{-} \geq 28.101 \mu \mathrm{V}$ & $\begin{array}{c}2.38 \\
(0.96,5.93)\end{array}$ & 0.062 & $\begin{array}{c}1.58 \\
(0.64,3.87)\end{array}$ & 0.319 & $\begin{array}{c}0.39 \\
(0.09,1.68)\end{array}$ & 0.203 & $\begin{array}{c}1.31 \\
(0.75,2.30)\end{array}$ & 0.341 \\
\hline $\mathrm{I}_{\mathrm{V} 3}^{-90} \geq 56.334 \mu \mathrm{V}$ & $\begin{array}{c}\mathbf{2 . 9 1} \\
(1.15,7.39)\end{array}$ & 0.024 & $\begin{array}{c}2.15 \\
(0.90,5.13)\end{array}$ & 0.084 & $\begin{array}{c}0.54 \\
(0.12,3.38)\end{array}$ & 0.414 & $\begin{array}{c}\mathbf{1 . 7 7} \\
(1.01,3.09)\end{array}$ & 0.047 \\
\hline $\mathrm{I}_{\mathrm{V} 3 \mathrm{X}}^{-} \geq 20.287 \mu \mathrm{V}$ & $\begin{array}{c}\mathbf{2 . 8 8} \\
(1.17,7.08)\end{array}$ & 0.021 & $\begin{array}{c}1.34 \\
(0.55,3.22)\end{array}$ & 0.519 & $\begin{array}{c}0.36 \\
(0.08,1.56)\end{array}$ & 0.173 & $\begin{array}{c}1.29 \\
(0.75,2.24)\end{array}$ & 0.356 \\
\hline $\mathrm{I}_{\mathrm{V} 3 \mathrm{X}}^{-90} \geq 34.133 \mu \mathrm{V}$ & $\begin{array}{c}\mathbf{3 . 7 6} \\
(1.49,9.48)\end{array}$ & 0.005 & $\begin{array}{c}\mathbf{2 . 7 2} \\
(1.21,6.14) \\
\end{array}$ & 0.016 & $\begin{array}{c}0.53 \\
(0.12,2.31) \\
\end{array}$ & 0.396 & $\begin{array}{c}\mathbf{2 . 1 2} \\
(1.24,3.62) \\
\end{array}$ & 0.006 \\
\hline $\mathrm{I}_{\mathrm{V} 2}^{90} \geq 28.86 \mu \mathrm{V}$ & $\begin{array}{c}\mathbf{2 . 6 6} \\
(1.07,6.63) \\
\end{array}$ & 0.035 & $\begin{array}{c}\mathbf{2 . 5 8} \\
(1.10,6.06) \\
\end{array}$ & 0.028 & $\begin{array}{c}0.45 \\
(0.10,1.93) \\
\end{array}$ & 0.280 & $\begin{array}{c}\mathbf{1 . 7 3} \\
(1.00,2.98) \\
\end{array}$ & 0.049 \\
\hline
\end{tabular}

SCD: Sudden cardiac death; PFD: Pump failure death; non-CD: non-cardiac death; HaR: Hazard ratio.

$\mathrm{I}_{\mathrm{v}_{2}}^{90}(+)$ and $\mathrm{I}_{\mathrm{v}_{2}}^{90}(-)$ by setting $t h_{\text {risk }}=28.86 \mu \mathrm{V}$, according to the total distribution of $\mathrm{I}_{\mathrm{v} 2}^{90}$ values. $\mathrm{I}_{\mathrm{v} 2}^{90}(+)$ classified patients were successfully associated with SCD outcome, with 2.66 increased risk compared to the negative group (see Table II). However, the index lost its predictive value if no restriction in HR was imposed $\left(\mathrm{I}_{\mathrm{V} 2}\right)$.

In order to test whether repolarization variations measured by the proposed indices are specifically associated with arrhythmia propensity, we have also computed the prognostic values of the proposed indices for other types of death of our cohort: cardiac death due to pump failure (PFD) and noncardiac death (non-CD), as well as for total mortality. We found that the only two indices associated with PFD were $\mathrm{I}_{\mathrm{V} 3 \mathrm{X}}^{-90}$ and $\mathrm{I}_{\mathrm{v} 2}^{90}$, with lower hazard ratios than when associated to SCD, while none of them were associated with non-cardiac death. When considering total mortality, $\mathrm{I}_{\mathrm{v}_{3}}^{+90}$ and $\mathrm{I}_{\mathrm{v} 3}^{-90}$, in addition to $\mathrm{I}_{\mathrm{v} 3 \mathrm{X}}^{-90}$ and $\mathrm{I}_{\mathrm{v} 2}^{90}$, resulted associated with death outcome but the obtained hazard ratios were lower than those obtained for SCD prediction. Note that total mortality outcome includes SCD as well as the other death types.

The Kaplan-Meier analysis for most significative indices is shown on Fig. 3. Clearly, mortality rates were always significantly higher in the positive $(+)$ group in comparison to patients classified as negative $(-)$ at the end of the follow-up period.

\section{A. Combination of $\mathrm{I}_{V 3}$ and $\mathrm{I}_{V 2}$}

An additional analysis was performed to assess whether the use of combined indices would improve SCD risk stratification. First, results derived from the analysis of $\mathrm{I}_{\mathrm{v} 3}^{-}$and $\mathrm{I}_{\mathrm{v} 3}^{+}$ were combined, then additional information from $\mathrm{I}_{\mathrm{v} 2}^{90}$ analysis was also included. Results from univariate model are shown in Table III. The combination of $\mathrm{I}_{\mathrm{v}_{3}}^{-}$and $\mathrm{I}_{\mathrm{v}_{3}}^{+}$improves the single stratification performance of $\mathrm{I}_{\mathrm{v} 3}^{-}$and $\mathrm{I}_{\mathrm{v} 3}^{+}$in most of
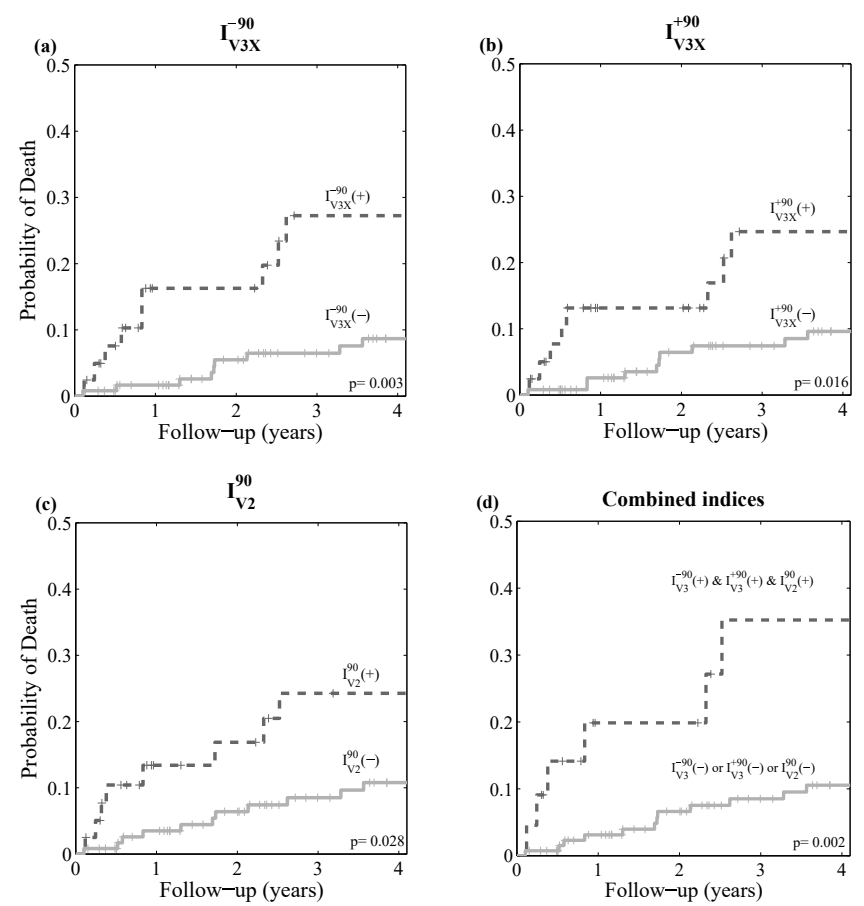

Fig. 3. Cumulative Kaplan-Meier probability curves for SCD associated to (a) $\mathrm{I}_{\mathrm{V} 3 \mathrm{X}}^{-90}$ (b) $\mathrm{I}_{\mathrm{V} 3 \mathrm{X}}^{+90}$, (c) $\mathrm{I}_{\mathrm{V} 2}^{90}$ and (d) combination of $\mathrm{I}_{\mathrm{V} 3}^{+90} \& \mathrm{I}_{\mathrm{V} 3}^{-90} \& \mathrm{I}_{\mathrm{V} 2}^{90}$ indices.

the cases. Nonetheless, better prognostic values are obtained when $\mathrm{I}_{\mathrm{v} 2}^{90}$ is also considered: the combination of patients that were simultaneously classified as $\mathrm{I}_{\mathrm{v} 3}^{-}(+), \mathrm{I}_{\mathrm{v} 3}^{+}(+)$and $\mathrm{I}_{\mathrm{v} 2}^{90}(+)$ in the individual analysis, identified patients with more than 4-fold increased risk of SCD in the univariate analysis. The best performance is obtained by considering patients at risk according to $\mathrm{I}_{\mathrm{v}_{3} \mathrm{X}}^{-}(+)$and $\mathrm{I}_{\mathrm{v} 3 \mathrm{X}}^{+}(+)$and $\mathrm{I}_{\mathrm{v} 2}^{90}(+)$ (i.e, the group of 
patients that were classified as positive in these three cases: $\mathrm{I}_{\mathrm{v}_{3} \mathrm{X}}^{-}(+) \& \mathrm{I}_{\mathrm{v}_{3} \mathrm{X}}^{+}(+) \& \mathrm{I}_{\mathrm{v}_{2}}^{90}(+)$ group) which presented more than 6 -fold increased risk of SCD. Kaplan-Meier survival curve is shown in Fig. 3 (d).

TABLE III

ASSOCIATION OF THE COMBINATION OF $\mathrm{I}_{\mathrm{V} 3}$ AND $\mathrm{I}_{\mathrm{V} 2}^{90}$ INDICES WITH SUDDEN CARDIAC DEATH IN PATIENTS WITH HEART FAILURE AND ATRIAL FIBRILLATION.

\begin{tabular}{|c|c|c|c|}
\hline & \multirow{2}{*}{$\begin{array}{c}\text { positive } \\
\text { patients } \\
(\%)\end{array}$} & \multicolumn{2}{|c|}{ Univariate } \\
\hline & & $\begin{array}{c}\text { HaR } \\
(95 \% \mathrm{CI})\end{array}$ & p-value \\
\hline$C 1=\mathrm{I}_{\mathrm{V} 3}^{+}(+) \& \mathrm{I}_{\mathrm{V} 3}^{-}(+)$ & $\begin{array}{c}37 \\
(21.6 \%)\end{array}$ & $\begin{array}{c}\mathbf{2 . 7 2} \\
(1.09,6.77)\end{array}$ & 0.031 \\
\hline$C 2=\mathrm{I}_{\mathrm{V} 3}^{+90}(+) \& \mathrm{I}_{\mathrm{V} 3}^{-90}(+)$ & $\begin{array}{c}36 \\
(21.1 \%)\end{array}$ & $\begin{array}{c}2.49 \\
(0.96,6.42)\end{array}$ & 0.06 \\
\hline$C 3=\mathrm{I}_{\mathrm{V} 3 \mathrm{X}}^{+}(+) \& \mathrm{I}_{\mathrm{V} 3 \mathrm{X}}^{-}(+)$ & $\begin{array}{c}32 \\
(18.7 \%)\end{array}$ & $\begin{array}{c}\mathbf{3 . 5 9} \\
(1.44,8.94)\end{array}$ & 0.006 \\
\hline$C 4=\mathrm{I}_{\mathrm{V} 3 \mathrm{X}}^{+90}(+) \& \mathrm{I}_{\mathrm{V} 3 \mathrm{X}}^{-90}(+)$ & $\begin{array}{c}32 \\
(18.7 \%) \\
\end{array}$ & $\begin{array}{c}\mathbf{3 . 2 2} \\
(1.25,8.33) \\
\end{array}$ & 0.016 \\
\hline$C 5=\mathrm{I}_{\mathrm{V} 3}^{+}(+) \& \mathrm{I}_{\mathrm{V} 3}^{-}(+) \& \mathrm{I}_{\mathrm{V} 2}^{90}(+)$ & $\begin{array}{c}19 \\
(11.1 \%)\end{array}$ & $\begin{array}{c}\mathbf{4 . 2 9} \\
(1.63,11.30)\end{array}$ & 0.003 \\
\hline$C 6=\mathrm{I}_{\mathrm{V} 3}^{+90}(+) \& \mathrm{I}_{\mathrm{V} 3}^{-90}(+) \& \mathrm{I}_{\mathrm{V} 2}^{90}(+)$ & $\begin{array}{c}22 \\
(12.9 \%)\end{array}$ & $\begin{array}{c}\mathbf{4 . 2 2} \\
(1.58,11.30)\end{array}$ & 0.004 \\
\hline$C 7=\mathrm{I}_{\mathrm{V} 3 \mathrm{X}}^{+}(+) \& \mathrm{I}_{\mathrm{V} 3 \mathrm{X}}^{-}(+) \& \mathrm{I}_{\mathrm{V} 2}^{90}(+)$ & $\begin{array}{c}15 \\
(8.8 \%)\end{array}$ & $\begin{array}{c}\mathbf{6 . 4 9} \\
(2.46,17.14)\end{array}$ & $<\mathbf{0 . 0 0 1}$ \\
\hline$C 8=\mathrm{I}_{\mathrm{V} 3 \mathrm{X}}^{+90}(+) \& \mathrm{I}_{\mathrm{V} 3 \mathrm{X}}^{-90}(+) \& \mathrm{I}_{\mathrm{V} 2}^{90}(+)$ & $\begin{array}{c}15 \\
(8.8 \%)\end{array}$ & $\begin{array}{c}\mathbf{4 . 4 7} \\
(1.59,12.61)\end{array}$ & 0.005 \\
\hline
\end{tabular}

LVEF: Left ventricular ejection fraction; HaR: Hazard ratio.

\section{B. Bivariate model including clinical information}

The prognostic value of significant clinical and pharmacological variables, including age, gender, NYHA class III, $\mathrm{LVEF} \leq 35 \%$, diabetes and antiarrhythmic drugs intake (betablockers, digoxin and amiodarone) was also individually evaluated. Only $\mathrm{LVEF} \leq 35 \%$ was associated to SCD outcome (HaR: $3.11(1.12,8.64), p=0.030)$ in our study population. We then constructed a bivariate model with each one of the proposed indices together with the $\mathrm{LVEF} \leq 35 \%$. Results are included in Table IV. We found that only indices $\mathrm{I}_{\mathrm{V} 3 \mathrm{X}}^{-90}$ and $\mathrm{I}_{\mathrm{V} 2}^{90}$ kept the prognostic value when combined with LVEF.

In these two cases where both the index and the LVEF were associated to SCD, we identified the group of patients at risk as those that were simultaneously classified at risk by both variables. That is, one group of patients at risk was composed by patients with $\mathrm{I}_{\mathrm{V}_{3 X}}^{-90} \geq t h_{\text {risk }}$ and $\mathrm{LVEF} \leq 35 \%$ and compared with the rest of patients at low-risk. In the same way, a second group at-risk was composed by patients with $\mathrm{I}_{\mathrm{v}_{2}}^{90} \geq t h_{\text {risk }}$ and $\mathrm{LVEF} \leq 35 \%$. In both cases, the group of patients at risk obtained from the combination of both variables presented more than a 4-fold increased risk in comparison to the rest of patients (see Table V), improving the hazard ratios obtained with just the ECG-based indices. When we evaluated the performance of combined ECG indices $(C 1$ to $C 8)$ together with the LVEF, we got an improved stratification of patients, remarkably for conditions from $C 5$ to $C 8$, in which probability of death in patients at risk is more than 6 times higher in comparison to the rest of patients at the end of the follow-up period.
TABLE IV

BIVARIATE MODELS FOR SUDDEN CARDIAC DEATH PREDICTION INCLUDING EACH $I_{\mathrm{V}}$ INDEX TOGETHER WITH THE LVEF.

\begin{tabular}{|c|c|c|c|c|}
\hline & \multicolumn{2}{|c|}{$I_{\mathbf{V}}$ index } & \multicolumn{2}{|c|}{ LVEF $\leq 35 \%$} \\
\hline & $\begin{array}{c}\text { HaR } \\
(95 \% \text { CI })\end{array}$ & p-value & $\begin{array}{c}\text { HaR } \\
(95 \% \mathrm{CI}) \\
\end{array}$ & p-value \\
\hline $\mathrm{I}_{\mathrm{V} 3 \mathrm{X}}^{+}(+)$ & $\begin{array}{c}2.36 \\
(0.93,5.96)\end{array}$ & 0.070 & $\begin{array}{c}2.54 \\
(0.86,7.27)\end{array}$ & 0.083 \\
\hline $\mathrm{I}_{\mathrm{V} 3 \mathrm{X}}^{+90}(+)$ & $\begin{array}{c}2.25 \\
(0.87,5.84) \\
\end{array}$ & 0.095 & $\begin{array}{c}\mathbf{3 . 2 9} \\
(1.05,10.29)\end{array}$ & 0.040 \\
\hline $\mathrm{I}_{\mathrm{V} 3}^{-90}(+)$ & $\begin{array}{c}2.41 \\
(0.94,6.17)\end{array}$ & 0.067 & $\begin{array}{c}\mathbf{3 . 3 7} \\
(1.09,10.36)\end{array}$ & 0.034 \\
\hline $\mathrm{I}_{\mathrm{V} 3 \mathrm{X}}^{-}(+)$ & $\begin{array}{c}2.36 \\
(0.94,5.91)\end{array}$ & 0.067 & $\begin{array}{c}2.62 \\
(0.92,7.43)\end{array}$ & 0.071 \\
\hline $\mathrm{I}_{\mathrm{V} 3 \mathrm{X}}^{-90}(+)$ & $\begin{array}{c}\mathbf{2 . 9 2} \\
(1.13,7.53)\end{array}$ & 0.026 & $\begin{array}{c}\mathbf{3 . 1 3} \\
(1.00,9.76)\end{array}$ & 0.050 \\
\hline $\mathrm{I}_{\mathrm{V} 2}^{90}(+)$ & $\begin{array}{c}\mathbf{2 . 5 5} \\
(1.03,6.36) \\
\end{array}$ & 0.044 & $\begin{array}{c}\mathbf{2 . 9 4} \\
(1.06,8.18)\end{array}$ & 0.039 \\
\hline
\end{tabular}

LVEF: Left ventricular ejection fraction; HaR: Hazard ratio.

TABLE $\mathrm{V}$

ASSOCIATION OF THE COMBINATION OF THE PROPOSED INDICES AND LEFT VENTRICULAR EJECTION FRACTION WITH SUDDEN CARDIAC DEATH IN PATIENTS WITH HEART FAILURE AND ATRIAL FIBRILLATION.

\begin{tabular}{lccc}
\hline \hline & positive & \multicolumn{2}{c}{ Univariate } \\
\cline { 3 - 4 } & patients & HaR & p-value \\
& $(\%)$ & $(95 \% \mathrm{CI})$ & \\
\hline $\mathrm{I}_{\mathrm{V} 3 \mathrm{X}}^{-90}(+) \& \mathrm{LVEF} \leq 35 \%$ & 28 & $\mathbf{4 . 8 6}$ & $\mathbf{0 . 0 0 1}$ \\
& $(16.4 \%)$ & $(1.91,12.34)$ & \\
$\mathrm{I}_{\mathrm{V} 2}^{90}(+) \& \mathrm{LVEF} \leq 35 \%$ & 23 & $\mathbf{4 . 7 0}$ & $\mathbf{0 . 0 0 1}$ \\
\hline & $(13.5 \%)$ & $(1.84,12.00)$ & \\
\hline & 26 & $\mathbf{3 . 6 9}$ & $\mathbf{0 . 0 0 6}$ \\
& $(15.2 \%)$ & $(1.45,9.38)$ & \\
$C 2 \& \mathrm{LVEF} \leq 35 \%$ & 24 & $\mathbf{3 . 4 7}$ & $\mathbf{0 . 0 1 2}$ \\
& $(14.0 \%)$ & $(1.32,9.15)$ & \\
$C 3 \& \mathrm{LVEF} \leq 35 \%$ & 24 & $\mathbf{4 . 2 0}$ & $\mathbf{0 . 0 0 3}$ \\
& $(14.0 \%)$ & $(1.65,10.67)$ & \\
$C 4 \& \mathrm{LVEF} \leq 35 \%$ & 24 & $\mathbf{3 . 4 1}$ & $\mathbf{0 . 0 1 3}$ \\
& $(14.0 \%)$ & $(1.29,9.00)$ & \\
\hline \multirow{2}{*}{$C 5 \& \mathrm{LVEF} \leq 35 \%$} & 15 & $\mathbf{6 . 9 1}$ & $<\mathbf{0 . 0 0 1}$ \\
& $(8.8 \%)$ & $(2.61,18.26)$ & \\
$C 6 \& \mathrm{LVEF} \leq 35 \%$ & 16 & $\mathbf{6 . 9 9}$ & $<\mathbf{0 . 0 0 1}$ \\
& $(9.4 \%)$ & $(2.63,18.58)$ & \\
$C 7 \& \mathrm{LVEF} \leq 35 \%$ & 13 & $\mathbf{8 . 7 1}$ & $<\mathbf{0 . 0 0 1}$ \\
& $(7.6 \%)$ & $(3.28,23.14)$ & \\
$C 8 \& \mathrm{LVEF} \leq 35 \%$ & 14 & $\mathbf{6 . 4 7}$ & $<\mathbf{0 . 0 0 1}$ \\
\hline \hline
\end{tabular}

LVEF: Left ventricular ejection fraction; HaR: Hazard ratio.

\section{DISCUSSION}

In this study we have proposed new indices able to quantify ventricular repolarization changes, suitable in the particular condition of atrial fibrillation, and we have evaluated their prognostic value in a chronic heart failure population with AF. We found that both the 3-beat index of ventricular repolarization variation, $\mathrm{I}_{\mathrm{v}_{3}}^{-90}$, and the 2-beat index of ventricular repolarization variation $\mathrm{I}_{\mathrm{v} 2}^{90}$, restricted to heart rates $>90$ beats/min, which quantify consecutive ventricular repolarization variations based on a selective beat averaging approach, were independent predictors of SCD in our study population. Interestingly, the computation of $\mathrm{I}_{\mathrm{v} 3}$ in a single-lead basis 
led to an improvement in the predictive value when using lead $\mathrm{X}\left(\mathrm{I}_{\mathrm{v} 3 \mathrm{X}}^{-}, \mathrm{I}_{\mathrm{v} 3 \mathrm{X}}^{-90}, \mathrm{I}_{\mathrm{v}^{3} \mathrm{X}}^{+}\right.$and $\left.\mathrm{I}_{\mathrm{v}_{3 \mathrm{X}}}^{+90}\right)$. This is not likely due to a predominant direction of the variations in the direction of lead $\mathrm{X}$, as $\mathrm{X}$ was not the lead where the values of the parameters were greater. Results suggest either that beat-tobeat variations in the horizontal left-to-right direction are more related to arrhythmic risk than variations in other directions (one possible hypothesis is that this direction is the one better reflecting apico-basal dispersion, being this the more relevant for arrhythmia risk), or that a more reliable measurement can be done in lead X. Further studies could shed light over this.

Moreover, risk stratification based on the combination of $I_{v_{3}}$ and $I_{v_{2}}^{90}$ indices provided with a better identification of patients at risk of SCD rather than individual indices. Among clinical and pharmacological variables, only $\mathrm{LVEF} \leq 35 \%$ was associated with SCD outcome in our study population. When combining repolarization variation ECG-indices with this clinical condition for patients' stratification, hazard ratios were in all cases greater than LVEF or ECG indices alone. In particular, probability of death in the group of patients at risk when $\mathrm{I}_{\mathrm{v} 3}$ and $\mathrm{I}_{\mathrm{v} 2}^{90}$ were combined with LVEF was more than 6 times higher compared to the rest of patients, reaching an hazard ratio of 8.7 in the best case. It is known that, although LVEF is not specific in SCD prediction, patients with low LVEF $(\leq 35 \%)$ present higher risk of SCD overall. Nevertheless, in order to improve ICD effectiveness and reduce SCD rates in the overall population, it is interesting the study of the stratification performance of the proposed indices in patients with preserved LVEF ( $>35 \%$ ). Although we found a better stratification in the $\mathrm{LVEF} \leq 35 \%$ group, the reduced number of SCD events in our population, especially in the preserved LVEF group (only 5 SCD events in patients with $\mathrm{LVEF}>35 \%$ ) limits statistical analysis in this group.

The approach based on selective beat averaging selected consecutive beats preceded by a similar $R R$ interval $(< \pm 20$ $\mathrm{ms}$ ), from which changes in ventricular repolarization were assessed using two different strategies. First, selecting triplets of stable beats, two indices were computed: $\mathrm{I}_{\mathrm{v} 3}^{+}$, measuring the average repolarization variation within the triplet, and $\mathrm{I}_{\mathrm{v} 3}^{-}$, which could be considered as a measurement of the average alternant variation in the triplet. The later arises as a first attempt in the assessment of instantaneous local alternans, as the irregular ventricular contraction rate during $\mathrm{AF}$ prevent from the evaluation of sustained TWA. However, as the irregularity in HR increases, it can become challenging to find 3-beats sequences with similar $R R$ along the Holter recording, and this can compromise the bin characterization. The second strategy, already proposed in a previous work [18], was an analysis initially restricted to only two consecutive stable ventricular repolarizations and, based on that, the 2-beat index of ventricular repolarization variation, $\mathrm{I}_{\mathrm{v} 2}^{90}$, was proposed. This adds the advantage that more stable pairs than triplets along the Holter recording resulted available to characterize each bin, leading to a potentially more robust estimation. In all cases, the positive association of higher repolarization variability with SCD outcome in our study population is in agreement with the fact that repolarization heterogeneity predispose to this fatal outcome in sinus rhythm patients [11]. Although our indices are not exactly measuring TWA, we hypothesize that they may be reflecting intrinsic heterogeneities of repolarization, dependent on both conduction velocity and inhomogeneity in action potential duration (APD) of cardiac myocytes. In the case of CHF hearts, for example, it is known that ion current remodelling and the prolongation of APD, which predispose to conduction block and re-entrant arrhythmias, generate repolarization heterogeneity that may be measured by the proposed indices [24].

Ventricular repolarization heterogeneity is a rate-dependent phenomenon, known to be accentuated with increased heart rates. In TWA analysis, for example, a target heart rate between $100-120$ beats/min is commonly used in the clinical practice [25]. In this work, a minimum of 90 beats/min has been considered. That value was obtained in our preliminary study as a trade-off between the predictability of the index and the number of patients where the indices were computable. This parameter was kept unchanged for all the proposed indices, and we did not intend to optimize its value so as to avoid the risk of overadaptation, due to the size of the database. However, we performed a sensitivity analysis, which revealed that most significative indices preserved also the prognostic value with hazard ratios $\geq 1$ for minimum heart rates ranging from 80 up to 110 beats/min, (from 70 beats/min when lead $\mathrm{X}$ was used). Similarly, the value of $\delta=40 \mathrm{~ms}$ represents a trade-off between the number of pairs/triplets suitable for the analysis and the required RR stability between consecutive beats. As stated for the minimum HR, the value of $\delta$ was not either optimized for each index to avoid overmatching our data. Nevertheless, a sensitivity analysis showed that most significative indices kept the prognostic value when $\delta$ was set in the range between 40 and $50 \mathrm{~ms}$. Further studies with bigger-size populations could try to fine-tune the parameters used for the computation of the indices.

It is also known that ventricular repolarization is very influenced by the heart rate in previous beats, with a memory that can attain 2-3 min [26, 27]. Therefore, it can be argued that beats that are averaged within a given bin may present different repolarization morphologies due to different $R R$ histories. However, the QT/RR slope, which expresses adaptation of ventricular repolarization to HR, has been shown to be decreased in AF compared to sinus rhythm [28]. Also, the most important effect is that of the HR in the previous beat, which is similar in all averaged beats. In the proposed method, the beats selected for averaging have stable instantaneous HR and they were averaged with other beats with similar previous HR. Also, due to the irregular series of $R R$ intervals that characterizes $\mathrm{AF}$, it can be expected that the effect of the different long-term histories will be small. Finally, the averaging is expected to fade the possible morphological differences, compensating the different $R R$ histories of the different pairs/triplets.

While the predictive value of several ECG-derived markers, mainly based on the assessment of ventricular repolarization heterogeneity has been largely demonstrated in sinus rhythm [12-16], the high irregularity in the ventricular response that characterizes AF limits the potential of those indices under this rhythm. Despite recent data have suggested SCD as the most common single cause of death in AF patients, rather than 
stroke or deaths from other cardiovascular origin [4, 29], studies about SCD stratification in patients with AF, in particular based on electrical instability in the ventricle, are scarce and the underlying mechanisms that associate $\mathrm{AF}$ and SCD are still intriguing. In some recent studies, it has been suggested that $\mathrm{AF}$ could be intrinsically pro-arrhythmic in the ventricle, increasing ventricular vulnerability and, consequently, SCD risk [5-8]. On the other hand, it has also been hypothesized that $\mathrm{AF}$ actually acts by means of other risk factors, as CHF, increasing SCD incidence [30, 31]. It is evident, therefore that a more comprehensive understanding of this phenomenon is still required to improve current treatment strategies. In this context, non-invasively ascertaining in what patients this proarrhythmic risk is higher, is crucial for the question of therapy decision-making.

Several independent predictors associated to SCD in AF populations have been proposed, including male sex, diabetes, history of myocardial infarction, heart failure, higher heart rate and left ventricular hypertrophy, among others [4, 29]. Also a previous study based on the $R R$ series extracted from high-resolution 20-minute ECG, which included 155 patients from our study group, showed that a reduced irregularity in the $R R$-interval series during $\mathrm{AF}$, measured in terms of approximate entropy, was able to predict all-cause death and $\mathrm{SCD}$, in contrast to traditional HRV indices [32]. However, as far as we know this is the first study in the attempt to non-invasively stratify CHF patients with AF at risk of SCD by assessing ventricular repolarization changes from the ECG signal. These results open the door to further research in the field. For example, the evaluation of the combination of indices based on ventricular repolarization dispersion together with the variability of the ventricular rate (HR-derived indices) may improve non-invasive stratification performance.

Still, some limitations need to be acknowledged. Although results obtained in this study have shown prognostic value in our study population, this population is limited in terms of the number of SCD events $(n=19)$. Therefore, further prospective studies in AF populations, with and without CHF, are needed in order to evaluate the actual clinical value of the indices. Moreover, this is a post hoc analysis and, as the MUSIC study was aimed at the evaluation of prognostic models in CHF not focused on the detailed analysis of AF, relevant information regarding the clinical course of $\mathrm{AF}$, such as duration, were not available.

\section{CONCLUSION}

In conclusion, increased ventricular repolarization beat-tobeat variation was associated to SCD in CHF patients with AF. Both $\mathrm{I}_{\mathrm{v}_{3}}^{-90}$ and $\mathrm{I}_{\mathrm{v}_{2}}^{90}$, computed from triplets and pairs of consecutive beats preceded by a similar $R R$ respectively, stratified AF patients according to their risk of SCD, with larger values associated to lower survival probability. In addition, risk assessment based on the combination of the proposed indices led to an improved prognostic value compared to the individual performance, with a better identification of high-risk patients. Although results should be confirmed in additional prospective studies, these results encourage further research on the evaluation of ventricular repolarization ECG-derived markers in future studies on patients with AF.

\section{REFERENCES}

[1] S. Chugh, R. Havmoeller, K. Narayanan, D. Singh, M. Rienstra, E. Benjamin, R. Gillum, Y. Kim, J. J. McAnulty, Z. Zheng, M. Forouzanfar, M. Naghavi, G. Mensah, M. Ezzati, and C. Murray, "Worldwide epidemiology of atrial fibrillation: A global burden of disease 2010 study," Circulation, vol. 129, no. 8, pp. 837-847, 2014.

[2] S. Colilla, A. Crow, W. Petkuun, D. Singer, T. Simon, and $\mathrm{X}$. Liu, "Estimates of current and future incidence and prevalence of atrial fibrillation in the u.s. adult population," Am. J. Cardiol., vol. 112, no. 8, pp. 1142-1147, 2013.

[3] W. Maisel and L. Stevenson, "Atrial fibrillation in heart failure: epidemiology, pathophysiology, and rationale for therapy," The American Journal of Cardiology, vol. 91, no. 6, pp. 2 - 8, 2003.

[4] E. Marijon, J.-Y. Le Heuzey, S. Connolly, S. Yang, J. Pogue, M. Brueckmann, J. Eikelboom, E. Themeles, M. Ezekowitz, L. Wallentin, and S. f. t. R.-L. I. Yusuf, "Causes of death and influencing factors in patients with atrial fibrillation," Circulation, vol. 128, no. 20, pp. 2192-2201, 2013.

[5] L. Chen, N. Sotoodehnia, P. Buzkov, and et al, "Atrial fibrillation and the risk of sudden cardiac death: The atherosclerosis risk in communities study and cardiovascular health study," JAMA Internal Medicine, vol. 173, no. 1, pp. 29-35, 2013.

[6] L. Chen, D. Benditt, and A. Alonso, "Atrial fibrillation and its association with sudden cardiac death," Circulation Journal, vol. 78, no. 11, pp. 2588-2593, 2014.

[7] P. Okin, C. Bang, K. Wachtell, D. Hille, S. Kjeldsen, B. Dahlöf, and R. Devereux, "Relationship of sudden cardiac death to newonset atrial fibrillation in hypertensive patients with left ventricular hypertrophyclinical perspective," Circulation: Arrhythmia and Electrophysiology, vol. 6, no. 2, pp. 243-251, 2013.

[8] A. Bardai, M. Blom, D. van Hoeijen, H. van Deutekom, H. Brouwer, and H. Tan, "Atrial fibrillation is an independent risk factor for ventricular fibrillation: large-scale populationbased case-control study," Circulation: Arrhythmia and Electrophysiology, vol. 7, no. 6, pp. 1033-1039, 2014.

[9] P. Laguna, J. Martínez, and E. Pueyo, "Techniques for ventricular repolarization instability assessment from the ECG," Proceedings of the IEEE, vol. 104, no. 2, pp. 392-415, 2016.

[10] M. Baumert, A. Porta, M. Vos, M. Malik, J. Couderc, P. Laguna, G. Piccirillo, G. Smith, L. Tereshchenko, and P. Volders, "QT interval variability in body surface ECG: measurement, physiological basis, and clinical value: position statement and consensus guidance endorsed by the european heart rhythm association jointly with the esc working group on cardiac cellular electrophysiology," Europace, vol. 18, no. 6, pp. 925 944, 2016.

[11] H. Wellens, P. Schwartz, F. Lindemans, A. Buxton, J. Goldberger, S. Hohnloser, H. Huikuri, S. Kb, L. Rovere, M. Teresa, M. Malik, R. Myerburg, M. Simoons, K. Swedberg, J. Tijssen, A. Voors, and A. Wilde, "Risk stratification for sudden cardiac death: current status and challenges for the future," European Heart Journal, vol. 35, no. 25, pp. 1642-1651, 2014.

[12] A. Montanez, J. Ruskin, P. Hebert, G. Lamas, and C. Hennekens, "Prolonged QTc interval and risks of total and cardiovascular mortality and sudden death in the general population: a review and qualitative overview of the prospective cohort studies," Archives of Internal Medicine, vol. 164, no. 9, pp. 943-948, 2004.

[13] C. Day, J. McComb, and R. Campbell, "QT dispersion: an indication of arrhythmia risk in patients with long QT intervals," Circulation, vol. 1, pp. 335-343, 1990.

[14] A. Mincholé, A Bueno-Orivio, P. Laguna, E. Pueyo, and B. Rodríguez, "ECG-based estimation of dispersion of APD restitution as a tool to stratify sotalol-induced arrhythmic risk," Journal of electrocardiology, vol. 48, pp. 867-873, 2015. 
[15] J. Couderc, M. Zhou, N. Sarapa, and W. Zareba, "Investigating the effect of sotalol on the repolarization intervals in healthy young individuals," Journal of electrocardiology, vol. 41, no. 6 , pp. 595-602, 2008.

[16] R. L. Verrier, T. Klingenheben, M. Malik, N. El-Sherif, D. V. Exner, S. H. Hohnloser, T. Ikeda, J. P. Martínez, S. M. Narayan, T. Nieminen, and D. S. Rosenbaum, "Microvolt Twave alternans physiological basis, methods of measurement, and clinical utility-consensus guideline by International Society for Holter and Noninvasive Electrocardiology," J. Am. Coll. Cardiol., vol. 58, no. 13, pp. 1309-1324, 2011.

[17] J. Ramírez, M. Orini, A. Mincholé, V. Monasterio, I. Cygankiewicz, A. Bayés-de Luna, J. Martínez, E. Pueyo, and P. Laguna, "Twave morphology restitution predicts sudden cardiac death in patients with chronic heart failure," Journal of the American Heart Association, vol. 6, no. 5, p. e005310, 2017.

[18] A. Martín-Yebra, I. Cygankiewicz, A. Bayés-de Luna, P. Laguna, E. Caiani, and J. Martínez, "Index of T-wave variation as a predictor of sudden cardiac death in chronic heart failure patients with atrial fibrillation," in Computing in Cardiology 2016, Sep. 2016, pp. 5-8.

[19] G. Moody and R. Mark, "Development and evaluation of a 2lead ECG analysis program." in Computers in Cardiology 1982, vol. 9, 1982, pp. 39-44.

[20] F. Badilini, P. Maison-Blanche, R. Childers, and P. Coumel, "QT interval analysis on ambulatory electrocardiogram recordings: a selective beat averaging approach," Medical \& Biological Engineering \& Computing, vol. 37, no. 1, pp. 71-79, Jan. 1999.

[21] A. Martín-Yebra, V. Monasterio, I. Cygankiewicz, A. Bayes-de Luna, E. Caiani, P. Laguna, and J. Martínez, "Post-ventricular premature contraction phase correction improves the predictive value of average t-wave alternans in ambulatory ecg recordings," IEEE Transactions on Biomedical Engineering, 2017.

[22] M. J. Bradburn, T. G. Clark, S. B. Love, and D. G. Altman, "Survival analysis part iii: Multivariate data analysis - choosing a model and assessing its adequacy adn fit." British Journal of Cancer, vol. 89, pp. 605-611, 2003.

[23] R. Vázquez, A. Bayés-Genis, I. Cygankiewicz, D. Pascual-Figal, L. Grigorian-Shamagian, R. Pavon, J. R. González-Juanatey, J. M. Cubero, L. Pastor, J. Ordonez-Llanos, J. Cinca, and A. B. d. Luna, "The MUSIC Risk score: a simple method for predicting mortality in ambulatory patients with chronic heart failure," European Heart Journal, vol. 30, no. 9, pp. 1088-1096, May 2009.

[24] G. Tse, S. T. Wong, V. Tse, Y. T. Lee, H. Y. Lin, and J. M. Yeo, "Cardiac dynamics: Alternans and arrhythmogenesis," Journal of Arrhythmia, vol. 35, no. 5, pp. 411-417, 2016.

[25] G. Turitto, E. B. Caref, G. ElAttar, M. Helal, A. Mohamed, R. P. Pedalino, and N. ElSherif, "Optimal target heart rate for exerciseinduced twave alternans." Annals of Noninvasive Electrocardiology, vol. 6, pp. 123-128, 2001.

[26] C. Lau, A. Freedman, S. Flemming, M. Malik, A. Camm, and D. Ward, "Hysteresis of the ventricular paced QT interval in response to abrupt changes in pacing rate," Cardiovascular Research, vol. 22, no. 2, pp. 67-72, 1988.

[27] E. Pueyo, P. Smetana, P. Caminal, A. Bayés-de Luna, M. Malik, and P. Laguna, "Characterization of QT interval adaptation to $\mathrm{RR}$ interval changes and its use as a risk-stratifier of arrhythmic mortality in amiodarone-treated survivors of acute myocardial infarction," IEEE Transactions on biomedical engineering, vol. 51, no. 9, pp. 1511-1520, 2004.

[28] A. Fujiki, R. Yoshioka, M. Sakabe, and S. Kusuzaki, "QT/RR relation during atrial fibrillation based on a single beat analysis in 24-h holter ECG: The role of the second and further preceding RR intervals in QT modification," Journal of Cardiology, vol. 57 , no. 3, pp. $269-274,2011$.

[29] A. Eisen, C. Ruff, E. Braunwald, F. Nordio, R. Corbaln, A. Dalby, M. Dorobantu, M. Mercuri, H. Lanz, H. Rutman,
S. Wiviott, E. Antman, and R. Giugliano, "Sudden cardiac death in patients with atrial fibrillation: Insights from the ENGAGE AFTIMI 48 trial," Journal of the American Heart Association, vol. 5, no. 7, p. e003735, 2016.

[30] K. Reinier, E. Marijon, A. Uy-Evanado, C. Teodorescu, K. Narayanan, H. Chugh, K. Gunson, J. Jui, and S. Chugh, "The association between atrial fibrillation and sudden cardiac death: the relevance of heart failure," JACC. Heart failure, vol. 2, no. 3, pp. 221-227, 2014.

[31] J. P. Piccini and J. P. Daubert, "Atrial fibrillation and sudden cardiac death: Is heart failure the middleman?," JACC: Heart Failure, vol. 2, no. 3, pp. 228-229, 2014.

[32] I. Cygankiewicz, V. Corino, R. Vazquez, A. Bayés-Genis, L. Mainardi, W. Zareba, A. Bayés-de Luna, P. Platonov, and MUSIC Trial Investigators, "Reduced irregularity of ventricular response during atrial fibrillation and long-term outcome in patients with heart failure," The American Journal of Cardiology, vol. 116, no. 7, pp. 1071-1075, 2015. 